\title{
The artificial tree (AT) algorithm
}

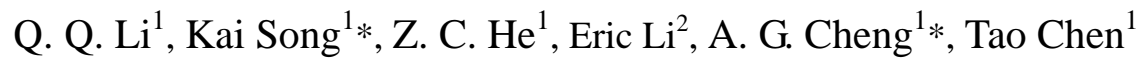 \\ ${ }^{1}$ State Key Laboratory of Advanced Design and Manufacturing for Vehicle Body, Hunan University, Changsha, 410082 P. \\ R. China \\ ${ }^{2}$ Department of Mechanical and Automation Engineering, The Chinese University of Hong Kong, Shatin, NT, Hong Kong, \\ China
}

\begin{abstract}
Bionic intelligence algorithms have many advantages compared with traditional optimization algorithms. In this paper, inspired by the growth law of trees, a new bionic algorithm, named artificial tree (AT) algorithm is developed. In the proposed AT, the branch position is considered as the design variable. In addition, the branch is the solution, and the branch thickness is the indicator of the solution. The computing process of AT is achieved by simulating the transport of organic matters and the update of tree branches. The comparative analysis using thirty typical benchmark problems between AT algorithm and some well-known bionic intelligent methods is also performed. Based on numerical results, AT is found to be very effective in dealing with various problems.
\end{abstract}

Key words: Numerical optimization; Bionic intelligent algorithm; Artificial tree algorithm;

* Corresponding author. Tel.: +86 18670000571, +86 13975100039 .

E-mail address: song_kaivip@163.com (Kai Song), cheng_aiguo@163.com (A. G. Cheng)

\section{Introduction}

Bionic intelligent algorithms are the important approaches to achieve the global optimization design [1-3]. Compared with classical optimization methods, bionic algorithms have more advantages in dealing with complex computational problems [4], such as transportation engineering [5, 6], image processing [7, 8], reactive power dispatch [9], pattern recognition [10]. As the bionics was proposed in 1950s, many works have been done by researchers about bionic algorithms. A lot of efficient bionic intelligent algorithms have been developed successfully, such as genetic algorithm (GA) [11-13], particle swarm optimization (PSO) algorithm [14, 15], differential evolution (DE) algorithm [16], simulated annealing (SA) algorithm [17, 18], artificial bee colony (ABC) algorithm [19-24] and gravitational search algorithm (GSA) [25]. The applications of these algorithms in different areas are analyzed extensively. However, each algorithm has its own advantages and disadvantages in the analysis of some specific problems [26]. Therefore, there is a compelling need to develop more efficient bionic intelligent algorithm.

Inspired by the transport of organic matters and the update of tree branches, a new algorithm named artificial tree (AT) algorithm is developed in this paper. Thirty well-known problems are applied to test the performance of AT. The results of AT are validated by comparing with other well-known bionic algorithms, and the excellent features of AT in dealing with various problems are proved clearly. 
This paper is organized as follows: the bionic model of AT is introduced in Section 2. Section 3 is the implementation flow of AT. Section 4 discusses the evolutionary strategies of other algorithms. Thirty benchmark functions and their numerical results calculated by seven bionic algorithms are analyzed in detail in Section 5 . Finally, Section 6 gives the conclusions of this paper.

\section{The theory of trees}

Trees are the most common plants in nature, and the common features of trees are described as follows: (1) Few branches are distributed in the lower part of trees and the lower branches are thick. (2) Thin branches always combine with other branches at the joint points to form thick branches. (3) There is always only one tree trunk in the bottom of the entire tree. In addition to the above common geometric features, the same organic matter transfer process is accompanied by the growth of trees. First, the organic matters are produced by photosynthesis in the leaves. Next, the organic matters are transferred to the adjacent twigs and then to the thick branches. Finally, the organic matters converge at the tree trunk.

In AT, the branch position represents the design variable, the branch denotes the solution and the thickness of each branch is the evaluation index of the solution. A thicker branch implies a better solution. The thickest tree trunk means the optimal solution. Due to the same direction of the branch update and the energy delivery, the transfer of organic matter depends mainly on the renewal of the branch. Therefore, the way to update the branch is the key of AT.

In this paper, there are three branch update ways which are the crossover behavior, the self-evolution behavior and the random behavior. The update theories to be applied depend on the branch density. On this basis, the concept of branch territory is proposed. This indicates that each branch has its own territory and the number of branches within one branch's territory cannot be too many. Once the branch number in one territory exceeds a certain number, the self-evolution behavior is selected as the update method. Otherwise, the crossover behavior takes over. As the updated branch is always thicker than the original one in natural, these two update ways require that the new solution must be better than the old one. If the new solution is worse than the original one, the new branch will be abandoned and another new branch will be found. A new estimate is carried out to judge whether this new branch meets the requirement. This cycle continues until a better solution appears. However, if the iteration number exceeds the maximum search number defined in advance, the third update way named the random behavior is applied in AT. The first and second ways are considered as the main update methods. The third way is regarded as a supplement one.

The behavior of trees is described in Fig. 1 to help us understand the implementation flow of AT. As shown in Fig. 1, it is assumed that the organic matters are produced by photosynthesis in the leaves and transferred to the adjacent branches. As the direction of branch update is the same as the transfer of organic matter, there are two options for the continuous delivery of organic matter which corresponds to the two update patterns (the crossover behavior and the self-evolution behavior) of branches. Then, the territory of each branch and the branch density within each territory are calculated to assist to estimate which renewal pattern is more reasonable for each branch. Next, these branches are updated and new thicker branches are found. These organic matters are passed to thicker branches. The process is repeated until the thickest tree trunk is reached. Thereby, the organic matter transfer process is from top to bottom and passes through all branches of the tree. It is noted that the entire process is always 
precise and efficient.

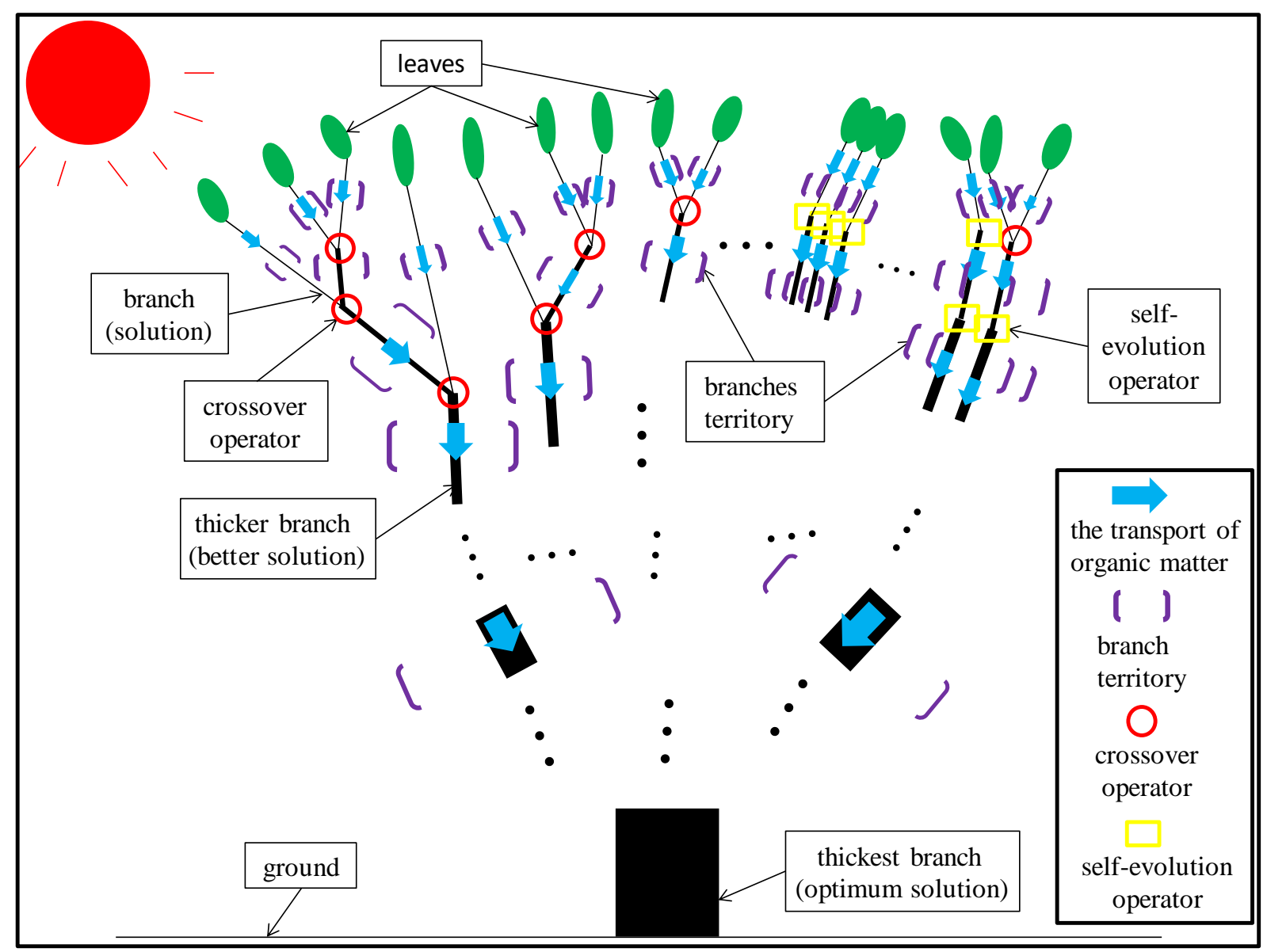

Fig. 1. The growth law of trees

\section{The implementation of artificial tree (AT) algorithm}

In AT, the transfer processes of organic matters are viewed as the optimization process of problems. It is supposed that the search space for the design variables is D-dimensional, the $i$-th branch position can be seen as a D-dimensional vector $\mathbf{x}_{i}=\left(x_{i l}, x_{i 2}, \ldots, x_{i D}\right), i=1,2, \ldots, S N, S N$ is the number of branches, $\mathrm{D}$ is the number of design variables. The implementation of the entire AT can be summarized as follows:

\subsection{Generate the initial branches}

In the initialization phase, some points in the design space are randomly selected as the initial branches population. The initial branch locations can be obtained by Eq. (1).

$x_{i j}=x_{i j}^{\min }+\operatorname{rand}(0,1) \times\left(x_{i j}^{\max }-x_{i j}^{\min }\right), i \in\{1,2, \ldots, S N\}, j \in\{1,2, \ldots, D\}$

where $x_{i j}^{\max }$ and $x_{i j}^{\min }$ are the upper and lower boundaries for the $j$-th variable of the $i$-th branch, $\operatorname{rand}(0,1)$ is a random number between the interval $[0,1]$. With these initial branches population, the initial solutions are calculated. Then, the optimal solution and its design variable in the first round of cycle are recorded as the best solution $f\left(\mathbf{x}_{\text {best }}\right)$ and the best design variable $\mathbf{x}_{\text {best. }}$, respectively. 


\subsection{Branch territory}

Each branch has its own territory and the overlap of territories occurs in the branch concentrated areas. Within one territory, the total number of branches existed should be limited to a certain range. A thicker branch has a larger territory which can be calculated by Eq. (2).

$\operatorname{Vi}\left(\mathbf{x}_{i}\right)=\left(L+L \times f i t\left(\mathbf{x}_{i}\right)\right) \times 2$

where $L$ is a constant, $V_{i}\left(\mathbf{x}_{i}\right)$ is the branch territory, $f i t\left(\mathbf{x}_{i}\right)$ is the fitness value of design variable $\mathbf{x}_{i}$. A better solution will have a larger $f i t\left(\mathbf{x}_{i}\right)$. For the minimum problem, the $f i t\left(\mathbf{x}_{i}\right)$ is calculated as follows:

$f i t\left(\mathbf{x}_{i}\right)=\left\{\begin{array}{lll}1 /\left(f\left(\mathbf{x}_{i}\right)+1\right) & \text { if } & f\left(\mathbf{x}_{i}\right) \geq 0 \\ 0 & \text { if } & f\left(\mathbf{x}_{i}\right)<0\end{array}\right.$

where $f\left(\mathbf{x}_{i}\right)$ is solution of the design variable $\mathbf{x}_{i}$.

The Euclidean distance between $i$-th and $j$-th individual branches is described as Eq. (4).

$\operatorname{Dis}_{i j}=\operatorname{norm}\left(\mathbf{x}_{i}-\mathbf{x}_{j}\right)$

where $\mathbf{x}_{i}$ and $\mathbf{x}_{j}$ are the $i$-th and $j$-th branches, respectively.

Based on the Euclidean distance, the crowded tolerance $T o l$ is proposed. Suppose the current branch position is $\mathbf{x}_{i}$, its territory can be expressed as $D i s_{i j}<\operatorname{Vi}\left(\mathbf{x}_{i}\right)$. We seek the number of other branches $N b$ within this territory. We compare the branches number $N b$ and the crowded tolerance $T o l$ to determine whether the branch territory is crowded.

\subsection{Self-evolution operator}

For current branch position $\mathbf{x}_{i}$, if $N b>T o l$, it means that it is crowded in current branch territory. The self-evolution operator is carried out to renew the branch. The mathematical expression of the self-evolution operator is given as follows:

$\mathbf{x}_{\text {new }}=\mathbf{x}_{i}+\operatorname{rand}(0,1) \times\left(\mathbf{x}_{\text {best }}-\mathbf{x}_{i}\right)$

where $\mathbf{x}_{b e s t}$ is the best branch location found so far.

\subsection{Crossover operator}

If $N b<=T o l$, the crossover operator is carried out to achieve the evolution of the branch. A branch is searched randomly within half of the branch territory and merged with current branch by stochastic linear interpolation. Then, the new branch is created and the mathematical model of this operator is given as follows:

$\mathbf{x}_{0}=\mathbf{x}_{i}+\operatorname{rand}(-1,1) \times\left(\operatorname{Vi}\left(\mathbf{x}_{i}\right) / 2\right)$

$\mathbf{x}_{\text {new }}=\operatorname{rand}(0,1) \times \mathbf{x}_{o}+\operatorname{rand}(0,1) \times \mathbf{x}_{i}$

where $\operatorname{rand}(-1,1)$ is a random number between -1 and 1 , and $\mathbf{x}_{o}$ is the searched branch location.

\subsection{Random operator}

Comparing the thickness of the new branch generated by the crossover operator or the self-evolution operator 
with the original branch, the new branch replaces the old one if the new one is thicker. Otherwise this new branch is rejected and another new branch continues to be generated by the crossover operator or the self-evolution operator. If the new branch is always worse than the original one and the search number reaches $L i$, we believe there is no better branch within this territory. Then, the random operator replaces the original operator and a new branch within the design space is randomly generated. The maximum search number $\operatorname{Li}\left(\mathbf{x}_{i}\right)$ in AT is calculated by Eq.(8) .

$$
\operatorname{Li}\left(\mathbf{x}_{i}\right)=N \times f i t\left(\mathbf{x}_{i}\right)+N
$$

where $N$ is a constant, $L_{i}\left(\mathbf{x}_{i}\right)$ is the maximum search number which is proportional to the fitness value $f i t\left(\mathbf{x}_{i}\right)$.

\subsection{Update the optimal value}

In order to acquire the thickest branch in current round of cycle, the solutions of each branch are compared with each other. For the minimum problem, the current round of optimum value is recorded as Eq. (9).

$f\left(\mathbf{x}_{c}^{\text {best }}\right)=\min \left(f\left(\mathbf{x}_{1}\right), f\left(\mathbf{x}_{2}\right), \ldots, f\left(\mathbf{x}_{S N}\right)\right)$

where $f\left(\mathbf{x}_{c}^{\text {best }}\right)$ and $\mathbf{x}_{c}^{\text {best }}$ are the best solution and best design variable in current cycle.

The new best solution is acquired by comparing best solutions between the previous and current cycle ones. If the best solution of current cycle is better, the solution and design variable are updated as the new best ones. Otherwise, keep the previous best solution and discard the best solution of current cycle. The implementation of the whole AT is described through the following pseudo-code.

Algorithm. The artificial tree algorithm

1: Objective Function $f(\mathbf{x})$

2: Set parameters of $L, N, T o l, B n$ and the maximum function evolution number (MEN)

3: Define the range of design variables

4: Initialize a population of $S N$ branches $\mathbf{x}=\left(\mathbf{x}_{l}, \ldots, \mathbf{x}_{S N}\right)$

5: Calculate the initial solutions $f(\mathbf{x})$ and record the initial best solution $f\left(\mathbf{x}_{\text {best }}\right)$ and the initial best design variable $\mathbf{x}_{i}$

6: $t=0$

7: while $t<M E N$

8: $\quad$ Calculate the maximum search number $\operatorname{Li}(\mathbf{x})$, the territory $\operatorname{Vi}(\mathbf{x})$ and the neighborhood $\operatorname{Dis}(\mathbf{x})$

9: $\quad$ Seek the number of branches $N b$ within the territory of each branch

10: $\quad$ for $i=1$ to $B n$ do

11: $\quad$ if $N b<=T o l$

12: $\quad \mathbf{x}_{0}=\mathbf{x}_{i}+\operatorname{rand}(-1,1) \times\left(\operatorname{Vi}\left(\mathbf{x}_{i}\right) / 2\right)$

13: $\quad \mathbf{x}_{\text {new }}=\operatorname{rand}(0,1) \times \mathbf{x}_{0}+\operatorname{rand}(0,1) \times \mathbf{x}_{i}$

14: $\quad$ if search number $<=L i$

15: $\quad$ if $f\left(\mathbf{x}_{\text {new }}\right)<f\left(\mathbf{x}_{i}\right)$

16: $\quad f\left(\mathbf{x}_{i}\right)=f\left(\mathbf{x}_{\text {new }}\right)$

17: $\quad \mathbf{x}_{i}=\mathbf{x}_{\text {new }}$

18: $\quad$ end if 


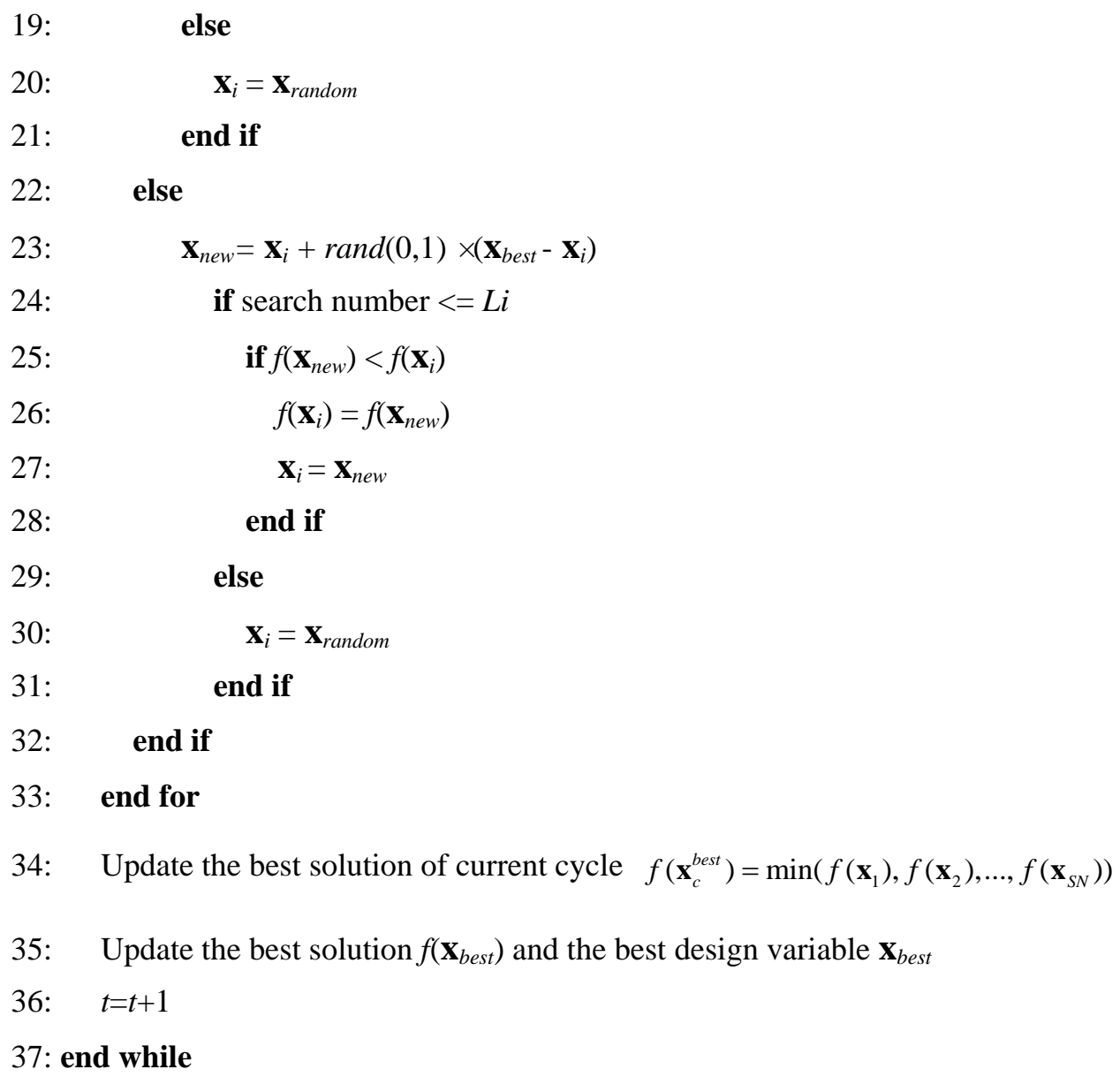

\section{Comparative study of evolutionary strategies}

\subsection{The genetic algorithm (GA)}

GA [27] was proposed based on the theory of survival of the fittest [28, 29]. Since it was put forward, many complicated problems [30-32] have been successfully solved due to its great efficiency. The realization of the basic genetic algorithm is based on five operation processes which are random number generation, fitness evaluation, reproduction operation, crossover operation and mutation operation.

In the initial stage of GA, a set of binary strings is randomly generated. Then, the fitness evaluation of each binary string is performed. The fitness values are the indicator to assess the solutions of each string. The reproduction operation is carried out by copying the string form one generation to the next generation. The reproduction process is also based on the fitness value of each string. The higher the fitness value of a string is, the greater the probability that it is selected to the next generation is. Then, the pairs of strings are randomly chosen by the crossover operation and the new pairs of strings are generated through exchanging chars at a randomly selected point of original parent strings. The mutation operation is a random mutation, which means the reversal of the value of a char on a string. Therefore, by performing the above four operations (fitness evaluation, reproduction operation, crossover operation and mutation operation) repeatedly, the new solutions are generated. 


\subsection{The particle swarm optimization (PSO) algorithm}

By simulating a flock of birds searching for food [33], the PSO was firstly presented by Eberhart and Kennedy in 1995. Because of the great performance of PSO in searching good solutions for various problems, a lot of studies $[34,35]$ have been conducted on it.

In PSO, one particle's position is considered as a solution. The optimization process is realized by continuous update of the position of these particles. In the iteration process of PSO, each particle is renewed by the best position of current particle and the global best position (achieved by all particles so far). Through the update of particle velocity, the particle can move to a new position at each time step $t$. The update of the velocity is obtained as follows:

$\mathrm{v}(t+1)=w \times \mathrm{v}(t)+c_{1} \times \operatorname{rand}(0,1) \times(\mathrm{p}(t)-\mathrm{x}(t))+c_{2} \times \operatorname{rand}(0,1) \times(\mathrm{g}(t)-\mathrm{x}(t))$,

where $c_{1}$ and $c_{2}$ are positive constants, $w$ is a weighting factor, and $\mathbf{v}(t)$ is the velocity vector.

Then, the position of the new particle is obtained by summing the previous particle position and the new particle velocity. The update of the particle position is achieved as Eq. (11).

$\mathrm{x}(t+1)=\mathrm{x}(t)+\mathrm{v}(t+1)$,

where $\mathbf{x}(t)$ is the position vector.

\subsection{The differential evolution (DE) algorithm}

DE has obtained a significant interest from researchers since it was proposed in 1995. A wide range of studies on DE was also carried out [36-39]. The optimization process of DE is realized by the similar operators of GA which are crossover, mutation and selection. Among them, the mutation operation and selection operation are the search mechanisms to determine the update direction of design variables in the design space.

Mutation operation should be carried out on each parameter vector. A solution of mutation vector $\mathrm{x}_{i}$ is calculated by Eq. (12).

$\mathrm{x}_{i}=\mathrm{x}_{r 1}+F\left(\mathrm{x}_{r 3}-\mathrm{x}_{r 2}\right)$,

where $F$ is the weight factor between 0 and 1 . The following Eq. (13) must be satisfied for these randomly selected solution vectors $\mathrm{X}_{r 1}, \mathrm{x}_{r 2}$ and $\mathrm{x}_{r 3}$.

$\mathrm{x}_{r 1}, \mathrm{x}_{r 2}, \mathrm{x}_{r 3} \mid r_{1} \neq r_{2} \neq r_{3} \neq i$

where $i$ represents the current solution.

For the crossover operator, the parent vector and mutated vector are mixed to generate new trial vectors through Eq. (14).

$\mathrm{y}_{i}^{j}= \begin{cases}\mathrm{x}_{i}^{j} & R_{j} \leq C R, \\ \mathrm{x}_{i}^{j} & R_{j}>C R,\end{cases}$

where $C R$ is crossover constant and $R_{j}$ is a random constant between 0 and $1, j$ is the $j$-th component of the corresponding array. 


\subsection{The gravitational search algorithm (GSA)}

The GSA was introduced in 2009 by Rashedi [25] Based on the theory of gravity field. In GSA, the objects have four properties: position, inertial mass, active gravitational mass, and passive gravitational mass. Due to the attraction of gravity, all objects move toward the heaviest object. Therefore, through the interaction of gravity, a direct communication is achieved between all objects. The position of an object represents a solution. A heavier object means a better solution which moves more slowly than the light one.

The calculation procedure of gravity force in GSA is summarized as follows:

The gravity force of mass $j$ acting on mass $i$ at a certain moment $t$ is calculated as Eq. (15).

$F_{i j}^{d}(t)=G(t) \times \frac{M_{p i}(t) \times M_{a j}(t)}{R_{i j}(t)+\varepsilon} \times\left(x_{j}^{d}(t)-x_{i}^{d}(t)\right)$,

where $M_{p i}$ is the passive gravitational mass of object $i, M_{a j}$ is the active gravitational mass of object $j, G(t)$ is the gravitational constant at time $t, \varepsilon$ is a small constant, $d$ is the dimension of variables, $R_{i j}(t)$ is the Euclidian distance between objects $i$ and $j$. The total force acting on object $i$ is the sum of the gravity forces from other objects with random weights.

$F_{i}^{d}(t)=\sum_{j=1, j \neq i}^{N} \operatorname{rand}_{j} \times F_{i j}^{d}(t)$

where $\operatorname{rand}_{j}$ is a random variable between 0 and 1.

The position of each object is updated as follows:

At time $\mathrm{t}$, the acceleration of object $i$ is calculated by Eq. (17).

$a_{i}^{d}(t)=\frac{F_{i}^{d}(t)}{M_{i i}(t)}$

where $M_{i i}$ is the inertial mass of $i$-th object.

The velocity of an object is calculated by its current velocity and acceleration. Therefore, the velocity and position are calculated by Eqs. (18) and (19).

$v_{i}^{d}(t+1)=\operatorname{rand}_{i} \times v_{i}^{d}(t)+a_{i}^{d}(t)$,

$x_{i}^{d}(t+1)=x_{i}^{d}(t)+v_{i}^{d}(t+1)$,

\subsection{The artificial bee colony (ABC) algorithm}

As a kind of swarm intelligence algorithm, $\mathrm{ABC}$ is obtained by simulating the foraging behavior of honey bee colony. Food source, employed forager and unemployed forager are the three main parts of ABC. Two major honeybee colony behavior patterns are to recruit and give up food source.

In $\mathrm{ABC}$, the food sources mean the solutions of problem. The amount of nectar in a food source stands for the merit of this solution. The probability that a food source is selected by unemployed foragers can be calculated by Eq. (20).

$p_{i}=f i t_{i} / \sum_{n=1}^{S N} f i t_{n}$

where $f i t_{i}$ is the fitness value of the solution $i$. A larger fitness value implies more nectar. $S N$ is the number of food 
sources which is equal to the number of employed bees.

The candidate food source is obtained through Eq. (21).

$v_{i j}=x_{i j}+\phi_{i j} \times\left(x_{i j}-x_{k j}\right)$

where $k \in\{1,2, \ldots, S N\}$ and $j \in\{1,2, \ldots, D\}, k$ is different from $i$ and selected randomly. $\phi_{i j}$ is a random number between interval -1 to 1 . If a position which is not been updated at a predetermined number of cycles, the corresponding old food source is abandoned and a new food source is generated randomly by Eq. (22).

$x_{i j}=x_{j}^{\min }+\operatorname{rand}(0,1) \times\left(x_{j}^{\max }-x_{j}^{\min }\right)$.

where $x_{j}^{\max }$ and $x_{j}^{\min }$ are the upper limit and lower limit of the $j$-th variable of vector $\mathbf{x}$.

\section{Numerical experiments}

\subsection{Benchmark functions}

In order to evaluate the performance of AT, thirty typical benchmark problems [40] are studied. As we can see from these benchmark functions, characteristic of these equations(C), dimension of the design variables (D), bound of the design spaces and the optimal solutions are listed in Tables 1 and 2. Three of these test functions are unimodal-seperable (US) problems, four are unimodal-nonseperable (UN) problems, five are multimodel-seperable (MS) problems and eighteen are multimodel-nonseperable (MN) functions. Parameters in problems Langerman, Fletcher - Powell, 3-parameter Hartman, 6-parameter Hartman, Kowalik and FoxHoles are given in [40]. For these test functions,

\subsection{Comparison between AT and GA, PSO, DE, GSA, ABC}

The results of AT are compared with other bionic algorithms (GA, PSO and DE, GSA and ABC). The maximum evaluation number for all problems is set to 400,000. Table 3 shows the other specific parameters of these algorithms. Thirty independent operations are performed with different random seeds for all test functions. Under the same condition, the results about means, standard deviations (SDs) and medians of these functions obtained by GA, PSO, DE, GSA, ABC and AT are listed. The result values which are less than $\mathrm{e}^{-20}$ are considered as 0 .

In order to avoid the familywise error and make a comprehensive comparison of these six algorithms, significant test is also used here. Five pairwise comparisons by t-test which are GA to AT, PSO to AT, DE to AT, GSA to AT and ABC to AT are applied. 
Table 1: Benchmark functions

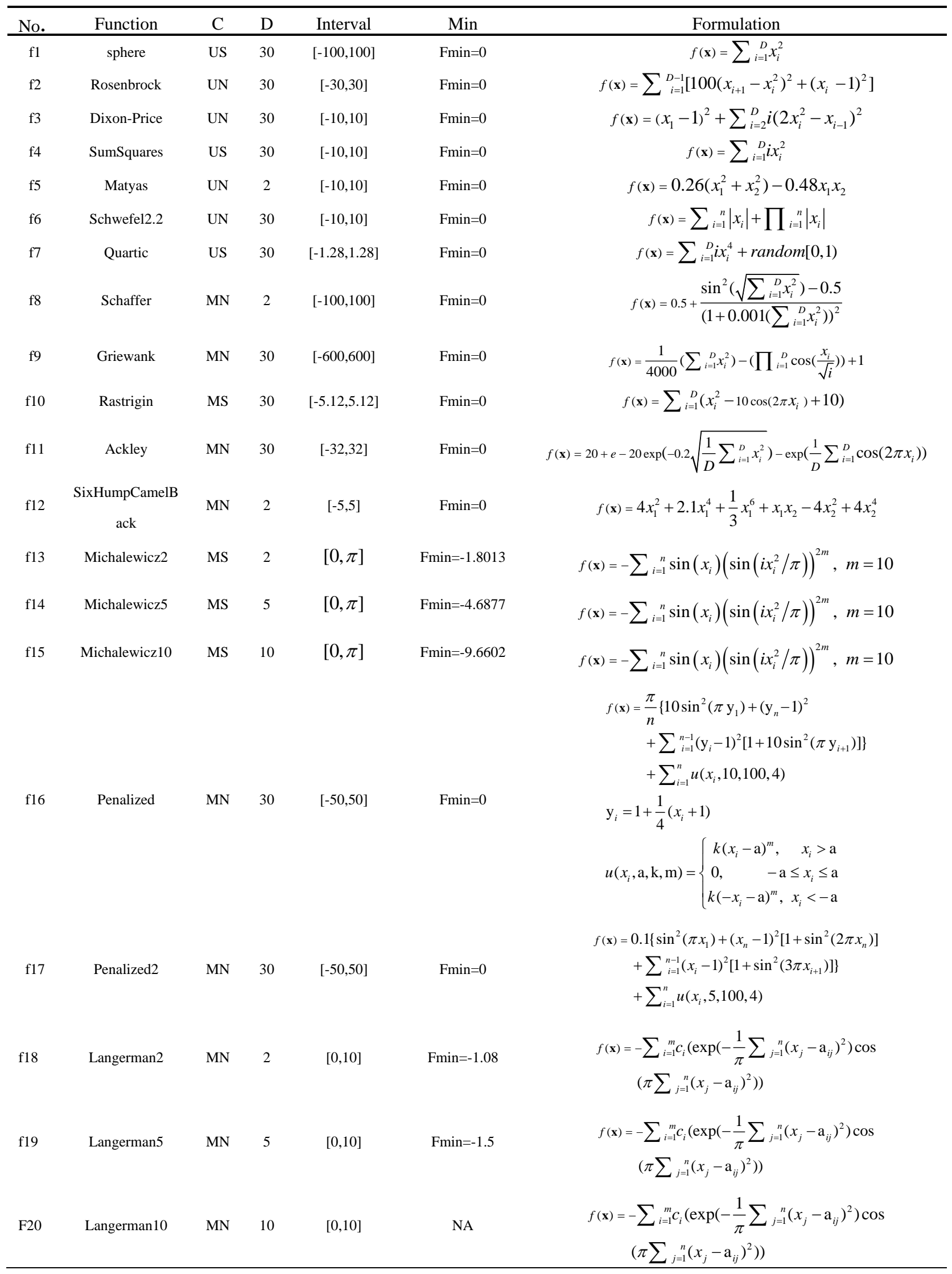


Table 2: Benchmark functions

\begin{tabular}{|c|c|c|c|c|c|c|}
\hline No. & Function & $\mathrm{C}$ & $\mathrm{D}$ & Interval & Min & Formulation \\
\hline f21 & FletcherPowell2 & MN & 2 & {$[-\pi, \pi]$} & Fmin $=0$ & $\begin{array}{l}f(\mathbf{x})=\sum_{i=1}^{n}\left(A_{i}-B_{i}\right)^{2} \\
A_{i}=\sum_{j=1}^{n}\left(a_{i j} \sin \alpha_{j}+b_{i j} \cos \alpha_{j}\right) \\
B_{i}=\sum_{j=1}^{n}\left(a_{i j} \sin x_{j}+b_{i j} \cos x_{j}\right)\end{array}$ \\
\hline $\mathrm{f} 22$ & FletcherPowell5 & $\mathrm{MN}$ & 5 & {$[-\pi, \pi]$} & Fmin $=0$ & $\begin{array}{l}f(\mathbf{x})=\sum_{i=1}^{n}\left(A_{i}-B_{i}\right)^{2} \\
A_{i}=\sum_{j=1}^{n}\left(a_{i j} \sin \alpha_{j}+b_{i j} \cos \alpha_{j}\right) \\
B_{i}=\sum_{j=1}^{n}\left(a_{i j} \sin x_{j}+b_{i j} \cos x_{j}\right)\end{array}$ \\
\hline $\mathrm{f} 23$ & FletcherPowell10 & MN & 10 & {$[-\pi, \pi]$} & Fmin $=0$ & $\begin{array}{l}f(\mathbf{x})=\sum_{i=1}^{n}\left(A_{i}-B_{i}\right)^{2} \\
A_{i}=\sum_{j=1}^{n}\left(a_{i j} \sin \alpha_{j}+b_{i j} \cos \alpha_{j}\right) \\
B_{i}=\sum_{j=1}^{n}\left(a_{i j} \sin x_{j}+b_{i j} \cos x_{j}\right)\end{array}$ \\
\hline $\mathrm{f} 24$ & Hartman3 & MN & 3 & {$[0,1]$} & Fmin $=-3.86$ & $f(\mathbf{x})=-\sum_{i=1}^{4} c_{i} \exp \left[-\sum_{j=1}^{3} a_{i j}\left(x-p_{i j}\right)^{2}\right]$ \\
\hline $\mathrm{f} 25$ & Hartman6 & MN & 6 & {$[0,1]$} & Fmin $=-3.32$ & $f(\mathbf{x})=-\sum_{i=1}^{4} c_{i} \exp \left[-\sum_{j=1}^{6} a_{i j}\left(x-p_{i j}\right)^{2}\right]$ \\
\hline f26 & Shekel5 & MN & 4 & {$[0,10]$} & Fmin $=-10.15$ & $f(\mathbf{x})=-\sum_{i=1}^{5}\left[\left(x-a_{i}\right)\left(x-a_{i}\right)^{T}+c_{i}\right]^{-1}$ \\
\hline $\mathrm{f} 27$ & Shekel7 & MN & 4 & {$[0,10]$} & Fmin $=-10.4$ & $f(\mathbf{x})=-\sum_{i=1}^{7}\left[\left(x-a_{i}\right)\left(x-a_{i}\right)^{T}+c_{i}\right]^{-1}$ \\
\hline $\mathrm{f} 28$ & Shekel10 & MN & 4 & {$[0,10]$} & Fmin $=-10.53$ & $f(\mathbf{x})=-\sum{ }_{i=1}^{10}\left[\left(x-a_{i}\right)\left(x-a_{i}\right)^{T}+c_{i}\right]^{-1}$ \\
\hline f29 & Kowalik & $\mathrm{MN}$ & 4 & {$[-5,5]$} & Fmin $=0.00031$ & $f(\mathbf{x})=\sum_{i=1}^{11}\left(a_{i}-\frac{x_{1}\left(b_{i}^{2}+b_{i} x_{2}\right)}{b_{i}^{2}+b_{i} x_{3}+x_{4}}\right)^{2}$ \\
\hline $\mathrm{f} 30$ & Foxholes & MS & 2 & {$[-65.536,65.536]$} & Fmin $=0.998$ & $f(\mathbf{x})=\left[\frac{1}{500}+\sum_{j=1}^{25} \frac{1}{j+\sum_{i=1}^{2}\left(x_{i}-a_{i j}\right)^{6}}\right]$ \\
\hline
\end{tabular}

Table 3: The other specific parameters of algorithms

\begin{tabular}{ccccccccccccc}
\hline \multicolumn{2}{c}{ GA [40] } & \multicolumn{2}{c}{ PSO [40] } & \multicolumn{2}{c}{ DE [40] } & \multicolumn{2}{c}{ GSA [25] } & \multicolumn{2}{c}{ ABC [41] } & \multicolumn{2}{c}{ AT } \\
\hline Pop & 50 & Pop & 50 & Pop & 50 & Pop & 50 & Pop & 50 & $B n$ & 50 \\
$C r$ & 0.8 & $\omega$ & 0.6 & $f$ & 0.5 & $G_{0}$ & 100 & Limit & Ne $\times D$ & $L$ & 0.5 \\
$M r$ & 0.01 & $\emptyset_{1}$ & 1.8 & Cr & 0.9 & $\alpha$ & 20 & $n s$ & 1 & $T o l$ & 1 \\
$G v$ & 0.9 & $\emptyset_{2}$ & 1.8 & & & $K_{0}$ & $N$ & & & $N$ & 10 \\
\hline
\end{tabular}

Pop, population size; $C r$, crossover rate for GA; $M r$, mutation rate; $G v$, generation gap value; $\omega$, Inertia weight; $\phi_{1}, \phi_{2}$, Cognitive and social components ; f, scaling factor; $\mathrm{Cr}$, crossover operation rate for $\mathrm{DE} ; G_{0}$, the value of the gravitational constant; $D$, dimension of the problem; ns, scout number; $B n$, branches number; $L$, constant which is used to describe the territory; Tol, congestion threshold value; $N$, constant which is used to describe the maximum search number.

Tables 4 - 7 show the results calculated by these algorithms. From Tables 4 and 5, it is seen that the results of AT are better than GA for twenty-seven problems, and the results of AT are the same as GA for one function. Compared with PSO, it is observed that AT gives better and similar solutions for twenty-one and two problems, respectively. In addition, it is found that the results of AT are better than GSA for all function. And the results from AT are more accurate compared with DE for sixteen functions and ABC for nineteen functions. Furthermore, it is noticed that the results of AT are the same as DE for six functions, and only one problem results are identical in AT and ABC algorithms. It is obvious that the results of AT are the best among all the algorithms. 
Table 4: The numerical results acquired by GA, PSO, DE, GSA, ABC and AT

\begin{tabular}{|c|c|c|c|c|c|c|c|c|}
\hline & Function & & GA & PSO & $\mathrm{DE}$ & GSA & $\mathrm{ABC}$ & $\mathrm{AT}$ \\
\hline \multirow{3}{*}{$\mathrm{f} 1$} & \multirow{3}{*}{ sphere } & Mean & 0.053619605 & 0.000244016 & 0.000589187 & 15.39657408 & $3.52914 \mathrm{E}-16$ & $5.1805 \mathrm{E}-21$ \\
\hline & & SD & 0.061500095 & $8.72817 \mathrm{E}-05$ & 0.000177295 & 1.390962279 & 4.81533E-16 & $1.33805 \mathrm{E}-20$ \\
\hline & & Median & 0.028346849 & 0.000222992 & 0.000525965 & 15.27736722 & $1.12134 \mathrm{E}-16$ & $5.70929 \mathrm{E}-22$ \\
\hline \multirow{3}{*}{$\mathrm{f} 2$} & \multirow{3}{*}{ Rosenbrock } & Mean & $4.67714 \mathrm{E}+02$ & 25.45703578 & 30308.49415 & 8700.608955 & 36.08743333 & 28.40877175 \\
\hline & & SD & $1.51148 \mathrm{E}+02$ & 2.967081761 & 18919.73833 & 1023.474846 & 24.93009734 & 0.010937968 \\
\hline & & Median & 463.5909396 & 25.82795899 & 22520.66201 & 8929.054953 & 26.9355 & 28.41046769 \\
\hline \multirow{3}{*}{ f3 } & \multirow{3}{*}{ Dixon-Price } & Mean & 16.82580422 & 0.666861993 & 8.862553927 & 1441.347363 & 0.666720467 & 0.706219945 \\
\hline & & SD & 5.927603941 & 0.00034661 & 1.539385682 & 349.5068593 & 0.00010999 & 0.003169242 \\
\hline & & Median & 16.86146498 & 0.666759857 & 8.731754922 & 1522.669246 & 0.666688 & 0.705717999 \\
\hline \multirow{3}{*}{$\mathrm{f} 4$} & \multirow{3}{*}{ SumSquares } & Mean & $3.36467 \mathrm{E}-03$ & $7.78595 \mathrm{E}-05$ & 7.67555E-05 & 213.8787801 & $1.61865 \mathrm{E}-17$ & $1.24063 \mathrm{E}-07$ \\
\hline & & SD & 0.0053694 & $2.05438 \mathrm{E}-05$ & $1.99597 \mathrm{E}-05$ & 19.04958672 & $1.89502 \mathrm{E}-17$ & $1.40281 \mathrm{E}-07$ \\
\hline & & Median & 0.000998472 & $8.32288 \mathrm{E}-05$ & 7.43307E-05 & 217.1944317 & $7.15098 \mathrm{E}-18$ & $5.95629 \mathrm{E}-08$ \\
\hline \multirow{3}{*}{ f5 } & \multirow{3}{*}{ Matyas } & Mean & 0.000557379 & 3.96179E-14 & 0 & $2.06488 \mathrm{E}-05$ & $1.01703 \mathrm{E}-10$ & 0 \\
\hline & & $\mathrm{SD}$ & 0.001062182 & $3.96661 \mathrm{E}-14$ & 0 & $1.38917 \mathrm{E}-05$ & $5.21904 \mathrm{E}-11$ & 0 \\
\hline & & Median & $3.86315 \mathrm{E}-05$ & 3.38773E-14 & 0 & $2.33644 \mathrm{E}-05$ & $1.25863 \mathrm{E}-10$ & 0 \\
\hline \multirow{3}{*}{ f6 } & \multirow{3}{*}{ Schwefel2.2 } & Mean & 0.041253292 & 0.011996062 & 4421.119267 & 17.07595047 & $1.43818 \mathrm{E}-13$ & 0.018799917 \\
\hline & & SD & 0.027235828 & 0.002821215 & 8246.35177 & 1.266347235 & $1.27884 \mathrm{E}-13$ & 0.007711746 \\
\hline & & Median & 0.040904202 & 0.011557182 & 1117.912318 & 17.30901041 & $8.76906 \mathrm{E}-14$ & 0.015778937 \\
\hline \multirow{3}{*}{$\mathrm{f} 7$} & \multirow{3}{*}{ Quartic } & Mean & 0.023473769 & 0.003449236 & 0.083715706 & 28.96811836 & 0.067065651 & 0.000505072 \\
\hline & & SD & 0.007209977 & 0.001206468 & 0.019711308 & 3.933660059 & 0.017857484 & 0.000325301 \\
\hline & & Median & 0.022299941 & 0.003289522 & 0.084888655 & 28.99555029 & 0.064893313 & 0.000507457 \\
\hline \multirow{3}{*}{ f8 } & \multirow{3}{*}{ Schaffer } & Mean & 0.016403693 & 0.001295455 & 0 & 0.004035269 & 0.000662968 & 0 \\
\hline & & $\mathrm{SD}$ & 0.012780972 & 0.003302774 & 0 & 0.003009398 & 0.000622665 & 0 \\
\hline & & Median & 0.00971591 & $1.68688 \mathrm{E}-10$ & 0 & 0.00395843 & 0.000474998 & 0 \\
\hline \multirow{3}{*}{ f9 } & \multirow{3}{*}{ Griewank } & Mean & 0.19097599 & 0.011202259 & 0.718472181 & 0.518253984 & $1.96286 \mathrm{E}-08$ & $2.03541 \mathrm{E}-15$ \\
\hline & & $\mathrm{SD}$ & 0.125980892 & 0.007070525 & 0.044564558 & 0.042478728 & 7.20925E-08 & $8.26518 \mathrm{E}-16$ \\
\hline & & Median & 0.141440668 & 0.011237077 & 0.722024629 & 0.518280755 & $2.38679 \mathrm{E}-11$ & $1.88738 \mathrm{E}-15$ \\
\hline \multirow{3}{*}{ f10 } & \multirow{3}{*}{ Rastrigin } & Mean & 2.157462674 & 24.83888191 & 256.1477144 & 206.0975653 & 200.5829333 & $1.12503 \mathrm{E}-14$ \\
\hline & & SD & 1.211747347 & 8.026313182 & 15.57230471 & 8.709554147 & 12.14668876 & $5.93302 \mathrm{E}-15$ \\
\hline & & Median & 2.02796164 & 24.87414468 & 262.6739427 & 205.7615253 & 204.057 & $1.06581 \mathrm{E}-14$ \\
\hline \multirow{3}{*}{ f11 } & \multirow{3}{*}{ Ackley } & Mean & 0.073282114 & 4.342413113 & 12.27705193 & 4.198500757 & $9.92382 \mathrm{E}-08$ & $6.89819 \mathrm{E}-14$ \\
\hline & & SD & 0.148450218 & 0.852502404 & 2.109803519 & 0.116299174 & 7.9071E-08 & $4.58776 \mathrm{E}-14$ \\
\hline & & Median & 0.029147998 & 4.4652903 & 13.02522813 & 4.200224749 & $7.56482 \mathrm{E}-08$ & $6.30607 \mathrm{E}-14$ \\
\hline & & Mean & -0.95022754 & -1.03162845 & -1.03162845 & -1.03144872 & -1.03162845 & -1.03162845 \\
\hline $\mathrm{f} 12$ & SixHumpCamelBack & SD & 0.11174564 & $5.92474 \mathrm{E}-12$ & 0 & 0.000200238 & $1.53316 \mathrm{E}-11$ & 0 \\
\hline & & Median & -1.00047015 & -1.03162845 & -1.03162845 & -1.03153067 & -1.03162845 & -1.03162845 \\
\hline & & Mean & -1.12323012 & -1.80130341 & -1.8012999 & -1.80107623 & -1.80130128 & -1.80130341 \\
\hline $\mathrm{f} 13$ & Michalewicz2 & SD & 0.219196987 & $5.69308 \mathrm{E}-12$ & $8.66987 \mathrm{E}-13$ & 0.000198127 & $1.44936 \mathrm{E}-12$ & $4.440892 \mathrm{E}-16$ \\
\hline & & Median & -0.99996999 & -1.80130341 & -1.80128872 & -1.80115064 & -1.8013034 & -1.80130341 \\
\hline & & Mean & -2.05683227 & -4.54695935 & -4.3918767 & -4.0302446 & -4.0967404 & -4.429383835 \\
\hline f14 & Michalewicz5 & SD & 0.232330184 & 0.269007858 & 0.0577059 & 0.2266156 & 0.1314988 & 0.220501687 \\
\hline & & Median & -1.99596894 & -4.64589536 & -4.40094241 & -4.04412371 & -4.11281577 & -4.495893207 \\
\hline & & Mean & -3.34082821 & -8.8322008 & -5.88452649 & -5.76321812 & -5.5568789 & -5.9638329 \\
\hline $\mathrm{f} 15$ & Michalewicz10 & $\mathrm{SD}$ & 0.715254451 & 0.545122392 & 0.216526592 & 0.226273221 & 0.460073624 & 0.2839840 \\
\hline & & Median & -3.27265533 & -8.97553978 & -5.7971786 & -5.73985832 & -5.345326 & -5.889523231 \\
\hline
\end{tabular}


Table 5: The numerical results acquired by GA, PSO, DE, GSA, ABC and AT

\begin{tabular}{|c|c|c|c|c|c|c|c|c|}
\hline & Function & & GA & PSO & $\mathrm{DE}$ & GSA & $\mathrm{ABC}$ & AT \\
\hline \multirow{3}{*}{ f16 } & \multirow{3}{*}{ Penalized } & Mean & 0.000271147 & 0.207457183 & 11.46815435 & 1.407545098 & 269.1495489 & 0.088094129 \\
\hline & & SD & 0.000586753 & 0.334547917 & 1.492521376 & 0.299622196 & 605.9155562 & 0.017111219 \\
\hline & & Median & 2.92431E-05 & 8.47294E-06 & 11.04572147 & 1.435421244 & 46.54250216 & 0.091456558 \\
\hline \multirow{3}{*}{$\mathrm{f} 17$} & \multirow{3}{*}{ Penalized2 } & Mean & 0.003105177 & 0.000807349 & 16.34877658 & 6.580311276 & 33.52676349 & 0.531771435 \\
\hline & & SD & 0.004009611 & 0.002738771 & 4.171298761 & 0.717003712 & 15.00425903 & 0.129141776 \\
\hline & & Median & 0.000604463 & $6.83874 \mathrm{E}-05$ & 16.2986135 & 6.441468193 & 30.1879651 & 0.521481417 \\
\hline \multirow{3}{*}{$\mathrm{f} 18$} & \multirow{3}{*}{ Langerman2 } & Mean & -0.45246506 & -0.89539155 & -1.08093844 & -1.08083394 & -1.08093826 & -1.080938442 \\
\hline & & $\mathrm{SD}$ & 0.28703011 & 0.21002886 & $2.22045 \mathrm{E}-16$ & $8.9318 \mathrm{E}-05$ & 1.40422E-07 & $1.98603 \mathrm{E}-16$ \\
\hline & & Median & -0.52050144 & -0.94562747 & -1.08093844 & -1.08085639 & -1.08093828 & -1.080938442 \\
\hline \multirow{3}{*}{ f19 } & \multirow{3}{*}{ Langerman5 } & Mean & -0.06997023 & -0.58682775 & -1.49999878 & -1.00694846 & -1.49967017 & -1.213767438 \\
\hline & & SD & 0.091634448 & 0.217910019 & $1.61269 \mathrm{E}-06$ & 0.170351153 & 0.000240984 & 0.321472145 \\
\hline & & Median & -0.03909339 & -0.51321311 & -1.49999922 & -0.9891567 & -1.49970577 & -1.465821651 \\
\hline \multirow{3}{*}{$\mathrm{f} 20$} & \multirow{3}{*}{ Langerman 10} & Mean & $-2.407 \mathrm{E}-05$ & -0.03305559 & -0.79895921 & -0.16372624 & -1.14829716 & -0.326106067 \\
\hline & & SD & $3.47232 \mathrm{E}-05$ & 0.041005017 & 0.004735426 & 0.072319476 & 0.153865444 & 0.17603243 \\
\hline & & Median & $-2.8188 \mathrm{E}-06$ & -0.00925707 & -0.79769379 & -0.13782546 & -1.14186181 & -0.355768736 \\
\hline \multirow{3}{*}{$\mathrm{f} 21$} & \multirow{3}{*}{ FletcherPowell2 } & Mean & $1.17531 \mathrm{E}-08$ & 47.01966399 & 0 & 0.062889363 & 0.026111273 & 0 \\
\hline & & $\mathrm{SD}$ & $2.24453 \mathrm{E}-08$ & 175.9314731 & 0 & 0.034318744 & 0.020833739 & 0 \\
\hline & & Median & $8.68726 \mathrm{E}-10$ & $1.7363 \mathrm{E}-09$ & 0 & 0.059727372 & 0.018203419 & 0 \\
\hline \multirow{3}{*}{$\mathrm{f} 22$} & \multirow{3}{*}{ FletcherPowell5 } & Mean & 390.9213647 & 1871.254714 & 0.982364268 & 521.0956005 & 335.5978016 & 67.2644496 \\
\hline & & $\mathrm{SD}$ & 704.3824004 & 1186.575987 & 0.598904285 & 177.6215568 & 176.3487774 & 85.1924839 \\
\hline & & Median & 12.53814604 & 2077.827648 & 0.983856213 & 538.7951752 & 350.5777082 & 33.1318967 \\
\hline \multirow{3}{*}{$\mathrm{f} 23$} & \multirow{3}{*}{ FletcherPowell10 } & Mean & 5192.327161 & 3949.295687 & 17555.46926 & 32248.43519 & 25722.3559 & 3554.4846608 \\
\hline & & $\mathrm{SD}$ & 6542.910271 & 9716.984865 & 5786.454248 & 8959.945507 & 6470.146486 & 2363.8132052 \\
\hline & & Median & 861.5039935 & 354.4526684 & 17577.65237 & 31626.2888 & 25270.82288 & 3371.711309 \\
\hline \multirow{3}{*}{$\mathrm{f} 24$} & \multirow{3}{*}{ Hartman3 } & Mean & -3.48638292 & -3.86278215 & -3.86278215 & -3.86187855 & -3.86278215 & -3.862426376 \\
\hline & & $\mathrm{SD}$ & 0.228696329 & $4.25842 \mathrm{E}-12$ & $1.77636 \mathrm{E}-15$ & 0.000392242 & $1.40433 \mathrm{E}-15$ & 0.000240651 \\
\hline & & Median & -3.50363097 & -3.86278215 & -3.86278215 & -3.86188616 & -3.86278215 & -3.862421724 \\
\hline \multirow{3}{*}{$\mathrm{f} 25$} & \multirow{3}{*}{ Hartman6 } & Mean & -1.48532936 & -3.26651171 & -3.32199517 & -3.19049997 & -3.32199517 & -3.27061395 \\
\hline & & $\mathrm{SD}$ & 0.438569478 & 0.05931431 & $8.88178 \mathrm{E}-16$ & 0.0247447 & $8.62592 \mathrm{E}-14$ & 0.072856518 \\
\hline & & Median & -1.55007312 & -3.32199517 & -3.32199517 & -3.17858915 & -3.32199517 & -3.321920563 \\
\hline \multirow{3}{*}{$\mathrm{f} 26$} & \multirow{3}{*}{ Shekel5 } & Mean & -5.11515515 & -6.29130885 & -10.1531997 & -6.961099 & -10.0719527 & -10.10278633 \\
\hline & & $\mathrm{SD}$ & 2.609257425 & 2.880134239 & $1.6537 \mathrm{E}-15$ & 1.440035404 & 0.120501903 & 0.188625298 \\
\hline & & Median & -3.91609897 & -5.10077214 & -10.1531997 & -6.78334694 & -10.1344541 & -10.15319967 \\
\hline & & Mean & -5.41972441 & -4.76750926 & -10.4029406 & -6.81072414 & -10.4016447 & -10.40241581 \\
\hline $\mathrm{f} 27$ & Shekel7 & SD & 2.777608826 & 2.887365775 & $3.27544 \mathrm{E}-15$ & 1.393472663 & 0.004847146 & 0.001963436 \\
\hline & & Median & -3.72430033 & -3.72430035 & -10.4029406 & -6.67162604 & -10.4029406 & -10.40294057 \\
\hline & & Mean & -5.36775544 & -5.23707903 & -10.5364098 & -6.75116119 & -10.5364098 & -10.53640633 \\
\hline $\mathrm{f} 28$ & Shekel10 & SD & 2.894419143 & 3.235661881 & $1.71612 \mathrm{E}-15$ & 1.31902797 & $2.35404 \mathrm{E}-08$ & $1.30363 \mathrm{E}-05$ \\
\hline & & Median & -3.8354268 & -3.8354268 & -10.5364098 & -6.88501612 & -10.5364098 & -10.53640982 \\
\hline & & Mean & 0.006858261 & 0.000368628 & 0.001023182 & 0.001119389 & 0.001106442 & 0.000315279 \\
\hline $\mathrm{f} 29$ & Kowalik & SD & 0.009376183 & 0.000228387 & $8.14757 \mathrm{E}-06$ & 0.000227809 & 5.81554E-05 & $2.91365 \mathrm{E}-05$ \\
\hline & & Median & 0.00251551 & 0.000307486 & 0.001027095 & 0.00100158 & 0.001088194 & 0.000307487 \\
\hline & & Mean & 0.998003838 & 1.064272309 & 0.998003838 & 0.9980119 & 0.998003844 & 0.998003838 \\
\hline $\mathrm{f} 30$ & Foxholes & $\mathrm{SD}$ & $3.58036 \mathrm{E}-16$ & 0.247953913 & 0 & $7.64015 \mathrm{E}-06$ & $1.12596 \mathrm{E}-08$ & $2.54788 \mathrm{E}-16$ \\
\hline & & Median & 0.998003838 & 0.998003838 & 0.998003838 & 0.998008988 & 0.99800384 & 0.998003838 \\
\hline
\end{tabular}

Five pairs of $t$ test at a significant level of 0.05 are shown in Tables 6 and 7. From Tables 6 and 7, the results of AT is still the best. The results of AT is better than GA on twenty-six problems and similar to it on two functions, better than PSO on twenty problems and similar to it on three functions, better than DE on fourteen functions and similar to it on eleven problems, better than GSA on all functions, better than ABC on nineteen functions and similar to it on four problems.

Fig. 2 illustrates the overall convergence rates of GA, PSO, DE, GSA, ABC and AT on these thirty benchmark equations. It is obvious that AT gives better accuracy in dealing with these problems. In addition, combined with 
Tables $4-7$, Fig. 2 clearly shows that the results of AT are better than the other five algorithms. Therefore, the excellent performance of AT is clearly proved.

Table 6: Five pairs of $t$ test results at a significant level of 0.05

\begin{tabular}{|c|c|c|c|c|c|}
\hline Function & GA & PSO & $\mathrm{DE}$ & GSA & $\mathrm{ABC}$ \\
\hline f1 & + & + & + & + & + \\
\hline $\mathrm{f} 2$ & + & - & + & + & + \\
\hline f3 & + & - & + & + & - \\
\hline $\mathrm{f} 4$ & + & + & + & + & - \\
\hline f5 & + & + & $\approx$ & + & + \\
\hline f6 & + & - & + & + & - \\
\hline f7 & + & + & + & + & + \\
\hline f8 & + & + & $\approx$ & + & + \\
\hline f9 & + & + & + & + & + \\
\hline f10 & + & + & + & + & + \\
\hline $\mathrm{f} 11$ & + & + & + & + & + \\
\hline f12 & + & + & $\approx$ & + & + \\
\hline f13 & + & + & $\approx$ & + & $\approx$ \\
\hline f14 & + & - & $\approx$ & + & + \\
\hline f15 & + & - & + & + & + \\
\hline f16 & - & + & + & + & + \\
\hline f17 & - & - & + & + & + \\
\hline $\mathrm{f} 18$ & + & + & $\approx$ & + & + \\
\hline f19 & + & + & - & + & - \\
\hline $\mathrm{f} 20$ & + & + & - & + & - \\
\hline $\mathrm{f} 21$ & + & + & $\approx$ & + & + \\
\hline f22 & + & + & - & + & + \\
\hline $\mathrm{f} 23$ & $\approx$ & $=$ & + & + & + \\
\hline $\mathrm{f} 24$ & + & - & - & + & - \\
\hline f25 & + & $=$ & - & + & - \\
\hline f26 & + & + & $\approx$ & + & $\approx$ \\
\hline f27 & + & + & $\approx$ & + & $\approx$ \\
\hline $\mathrm{f} 28$ & + & + & $\approx$ & + & $\approx$ \\
\hline f29 & + & $=$ & + & + & + \\
\hline $\mathrm{f} 30$ & $\approx$ & + & $\approx$ & + & + \\
\hline
\end{tabular}

Note: "+" and "-" mean the t value is significant, and the "+" and "-" represent the better and worse result, respectively. " $\approx$ " denotes that the $t$ value is not significant and the result of the compared algorithms is almost the same as AT.

Table 7: Comparison between AT and each of GA, PSO, DE, GSA and ABC based on t test.

\begin{tabular}{cccccc}
\hline Function & GA & PSO & DE & GSA & ABC \\
\hline AT better & 26 & 20 & 14 & 30 & 19 \\
AT worse & 2 & 7 & 5 & 0 & 7 \\
AT equal & 2 & 3 & 11 & 0 & 4 \\
success Rate & $93.33 \%$ & $76.67 \%$ & $83.33 \%$ & $100.00 \%$ & $76.67 \%$ \\
\hline
\end{tabular}

Note: "AT better" indicates the results of AT is better than the compared algorithms, "AT worse" indicates the results of AT is worse than the compared algorithms, "AT equal" indicates the results of AT is almost the same as the compared algorithms, and "Success Rate" is the success ratio of AT for all functions (including the AT equal and AT better ones). 

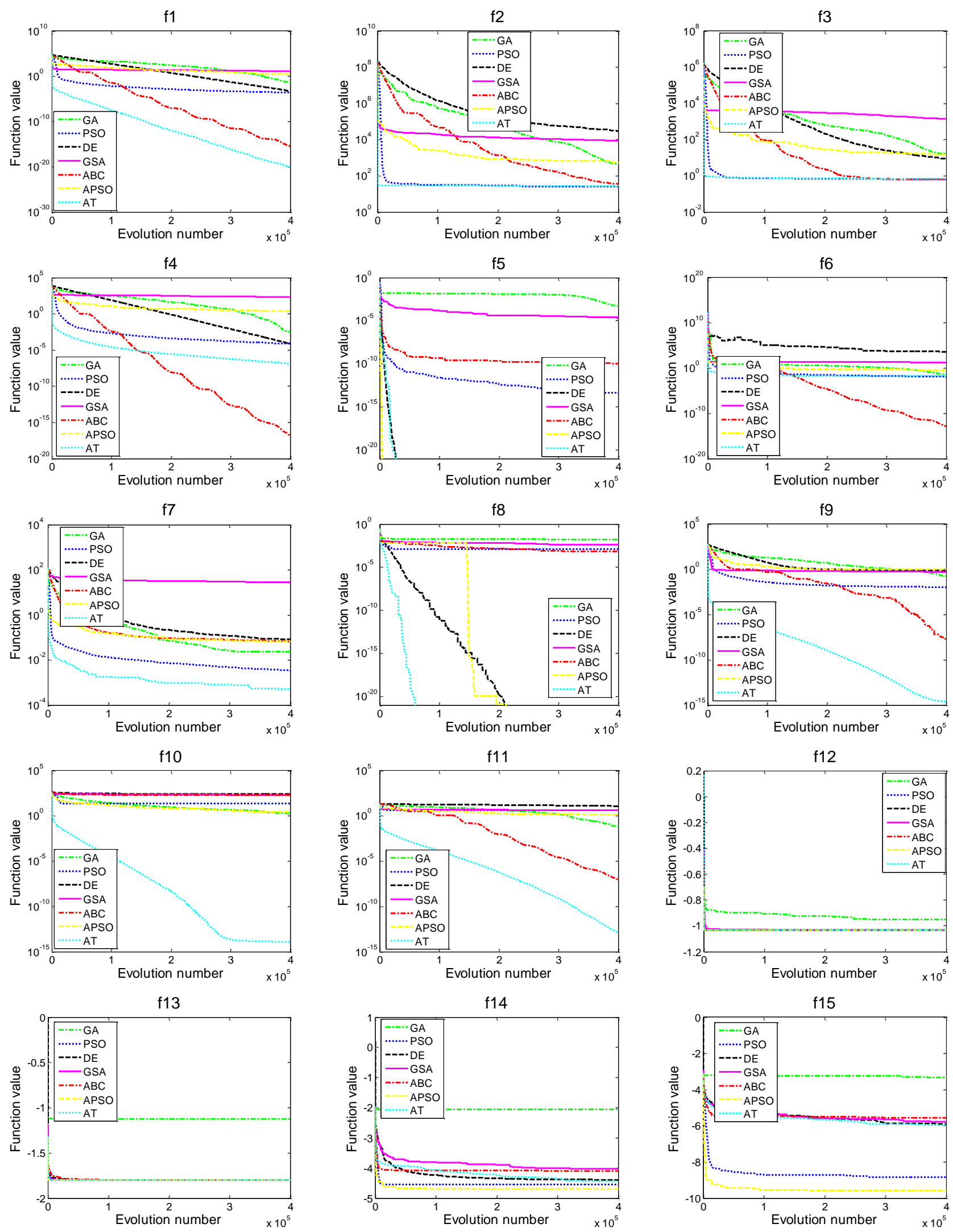

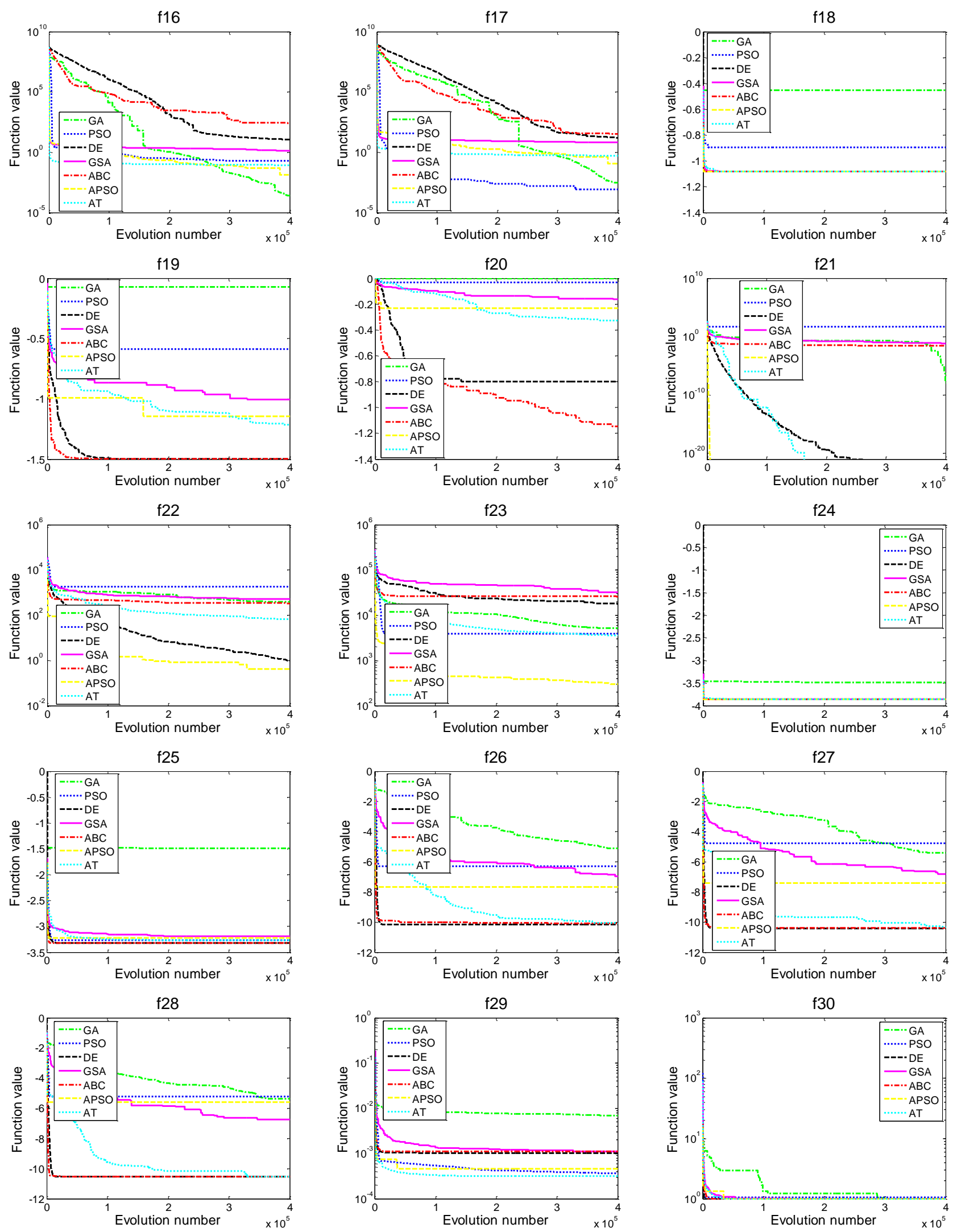

Fig. 2. Convergence performance of each algorithm on the thirty test functions 


\subsection{Comparison between AT and adaptive particle swarm optimization algorithm}

In Section 5.2, the excellent accuracy of AT is proved by comparing with various algorithms. Furthermore, an improved PSO named the adaptive particle swarm optimization (APSO) algorithm is applied in this section to further study AT. Thirty test functions listed in Tables 1 and 2 are applied here to test these two algorithms. Means, SDs and medians of these problems obtained by thirty independent operations of APSO and AT are presented in Table 8 . The maximum evaluation number for all test problems is set to 400,000 . The other specific parameters of APSO are from [42].

Table: 8 Experimental results obtained by APSO and AT.

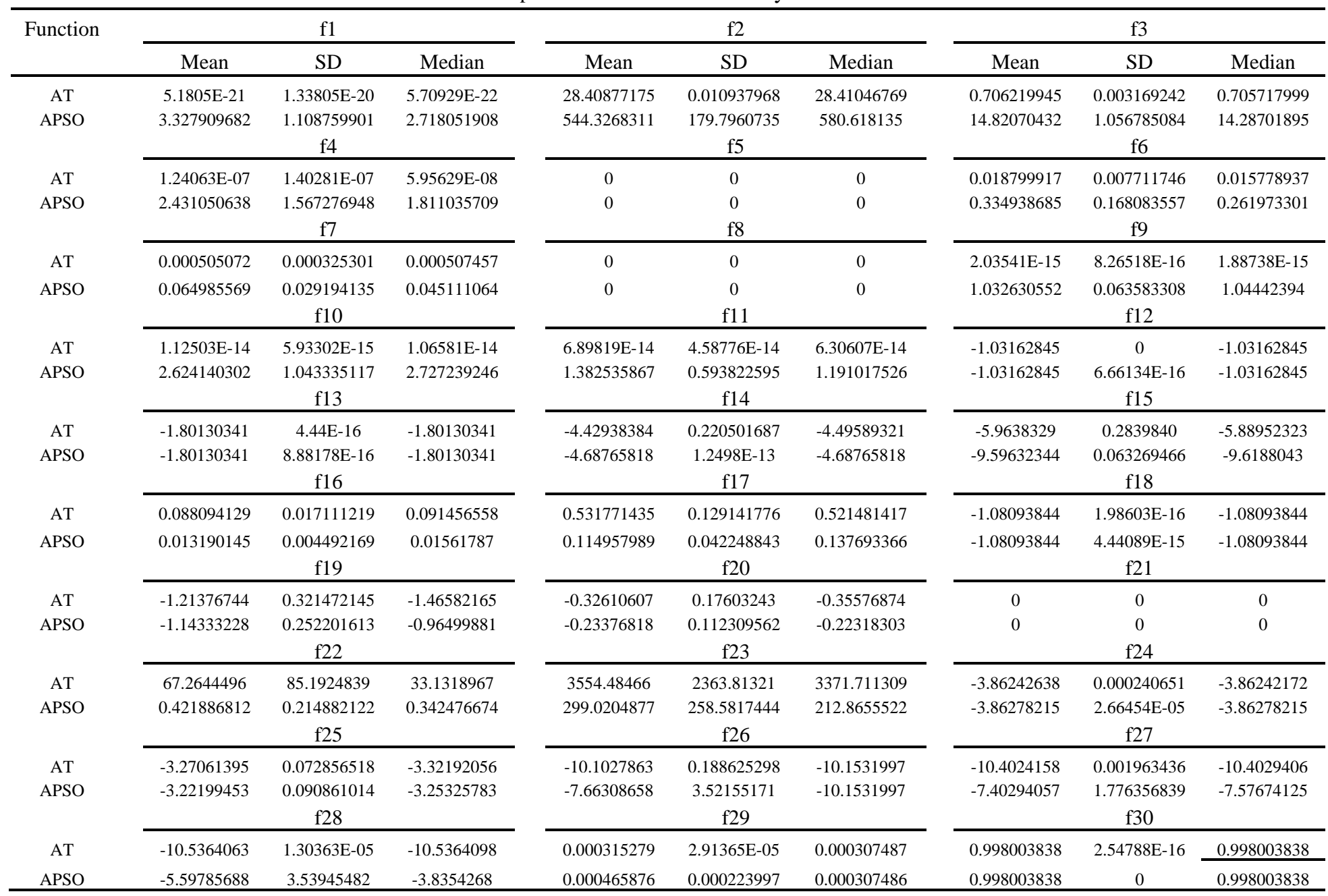

Table 9: Comparison results between APSO and AT based on $\mathrm{t}$ test.

\begin{tabular}{cccccccccccccccc}
\hline Function & $\mathrm{f} 1$ & $\mathrm{f} 2$ & $\mathrm{f} 3$ & $\mathrm{f} 4$ & $\mathrm{f} 5$ & $\mathrm{f} 6$ & $\mathrm{f} 7$ & $\mathrm{f} 8$ & $\mathrm{f} 9$ & $\mathrm{f} 10$ & $\mathrm{f} 11$ & $\mathrm{f} 12$ & $\mathrm{f} 13$ & $\mathrm{f} 14$ & $\mathrm{f} 15$ \\
\hline \multirow{2}{*}{ APSO } & + & + & + & + & $\approx$ & + & + & $\approx$ & + & + & + & $\approx$ & $\approx$ & - & - \\
& $\mathrm{f} 16$ & $\mathrm{f} 17$ & $\mathrm{f} 18$ & $\mathrm{f} 19$ & $\mathrm{f} 20$ & $\mathrm{f} 21$ & $\mathrm{f} 22$ & $\mathrm{f} 23$ & $\mathrm{f} 24$ & $\mathrm{f} 25$ & $\mathrm{f} 26$ & $\mathrm{f} 27$ & $\mathrm{f} 28$ & $\mathrm{f} 29$ & $\mathrm{f} 30$ \\
APSO & - & - & $\approx$ & $\approx$ & + & $\approx$ & - & - & - & + & + & + & + & + & $\approx$ \\
\hline
\end{tabular}

Note: "+" and "-" indicate that the t value is significant, and the "+" and "-." represent the better and worse result, respectively. " $\approx$ " denotes that the $t$ value is not significant and the value of APSO is almost the same as AT. 
Table 10: Comparison between APSO and AT on t test.

\begin{tabular}{ccccc}
\hline Function & AT better & AT worse & AT equal & success Rate \\
\hline APSO & 15 & 7 & 8 & $76.67 \%$ \\
\hline
\end{tabular}

Note: "AT better" indicates the result of AT is better than APSO, "AT worse" indicates the result of AT is worse than APSO, "AT equal" indicates the result of AT is almost the same as APSO, and "Success Rate" is the success ratio of AT for all functions (including the AT equal and AT better ones).

The comparison results between AT and APSO are presented in Tables 8 - 10 and Fig. 2. From Table 8 and Fig. 2, it is seen that the calculation results of AT is better than APSO. Regarding the problems f1- f4, f6, f7, f9 - f11, $\mathrm{f} 19, \mathrm{f} 20, \mathrm{f} 25$ - f29, only AT obtains the optimum solution. In addition, it is noticed that both AT and APSO find the best solutions of functions $\mathrm{f} 5, \mathrm{f} 8, \mathrm{f} 12, \mathrm{f} 13, \mathrm{f} 18, \mathrm{f} 21, \mathrm{f} 30$. The results of AT are better than APSO for sixteen problems, but the solutions are the same using AT and APSO for seven functions. Meanwhile, from Tables 9 and 10 , the t-test at a 0.05 significance is also performed. The results of AT is significantly better than APSO for functions $\mathrm{f} 1-\mathrm{f} 4, \mathrm{f} 6, \mathrm{f} 7, \mathrm{f} 9$ - $\mathrm{f} 11, \mathrm{f} 20, \mathrm{f} 25$ - $\mathrm{f} 29$. As t value is not significant for functions $\mathrm{f} 5, \mathrm{f} 8, \mathrm{f} 12, \mathrm{f} 13, \mathrm{f} 18, \mathrm{f} 19, \mathrm{f} 21, \mathrm{f} 30$, the performance of APSO is almost the same as AT. In summary, the AT gives better results compared with APSO for fifteen problems, and the results are similar between these two algorithms for eight functions. Therefore, based on the number of optimum solutions, the effectiveness of AT is very obvious compared with APSO.

The outstanding features of AT are validated again in this numerical example, which is due to the cooperation between the branch territory strategy, the crowded strategy and the update method of branch. All these strategies constitute the selection evolution theory of branches.

\section{Conclusion}

Inspired by the growth law of trees, the artificial tree (AT) algorithm is proposed in this paper. The transfer process of organic matters between different tree branches and the update approaches of branches form the computational flow of AT. Thirty standard benchmark problems are applied to test this algorithm. The performance of AT has been compared with some widely proved algorithms, including: genetic algorithm (GA), particle swarm optimization (PSO) algorithm, differential evolution (DE) algorithm, gravitational search algorithm (GSA), artificial bee colony (ABC) algorithm and adaptive particle swarm optimization (APSO) algorithm. The high efficiency of AT in dealing with various problems is proved. These numerical results have clearly demonstrated that this new algorithm is feasible, accurate and robust. The excellent performance of AT could be extended to more complicated problems in the future study.

\section{References}

[1] Eiben A E, Smith J E. Introduction to evolutionary computing. Heidelberg: springer, 2003.

[2] Kennedy J, Kennedy J F, Eberhart R Cl. Swarm intelligence. Morgan Kaufmann, 2001.

[3] Back T. Evolutionary algorithms in theory and practice: evolution strategies, evolutionary programming, genetic algorithms. Oxford university press, 1996.

[4] Vesterstrom J, Thomsen R. A comparative study of differential evolution, particle swarm optimization and evolutionary algorithms on numerical benchmark problems. Evolutionary Computation, 2004. CEC2004. Congress on. IEEE, 2004; 2: 1980-1987. 
[5] Wei Chiang H. Traffic flow forecasting by seasonal SVR with chaotic simulated annealing algorithm. Neurocomputing 2011; 74: 2096-2107.

[6] Wei Li Ming, Feng Han D, longWang W. Vessel traffic flow forecasting by RSVR with chaotic cloud simulated annealing genetic algorithm and KPCA. Neurocomputing 2015; 157: 243-255.

[7] Mojtaba Ghasemi, Mohammad Mehdi Ghanbarian, Sahand Ghavidel. Modified teaching learning algorithm and double differential evolution algorithm for optimal reactive power dispatch problem: A comparative study. Information Sciences 2014; 278: 231 - 249.

[8] Cordon O, Damas S, Santamar J. A fast and accurate approach for 3D image registration using the scatter search evolutionary algorithm, Pattern Recognition Letters 2006; 27(11): 1191 - 1200.

[9] Nezamabadi-pour H, Saryazdi S, Rashedi E. Edge detection using ant algorithms, Soft Computing 2006; 10(7): $623-628$.

[10] Tan X, Bhanu B. Fingerprint matching by genetic algorithms, Pattern Recognition 2006; 39(3): 465 - 477.

[11] Beyer H G. The theory of evolution strategies. Springer Science \& Business Media, 2013.

[12] Goldberg DE, Genetic Algorithm in Search Optimization and Machine Learning, Addison-Wesley 1989.

[13] Goldberg DE. The Design of Innovation: Lessons From and Component Genetic Algorithms, Kluwer Academic Publishers, Boston, MA, 2002.

[14] Kennedy J, Eberhart R, Particle Swarm Optimization, in: IEEE International Conference on Neural Networks, Perth, Australia, 1995, pp. 1942-1948.

[15] Parsopoulos KE, Plagianakos VP, Magoulas GD, Vrahatis MN. Objective function "stretching" to alleviate convergence to local minima, Nonlinear Analysis. 2001; 47 (5): 3419-3424.

[16] Storn, R, Price K. Differential Evolution: A Simple and Efficient Adaptive Scheme for Global Optimization over Continuous Spaces. Journal of Global Optimization 1995; 23(4):341-359.

[17] Metropolis N. Equations of state calculations by fast computing machines. Journal of Chemical Physics 1952; 21(6): 1087-1092.

[18] Kirkpatrick S, Gelatt CD, Vechi MP. Optimization by simulated annealing. Science 1983; 220(4598): 671-680.

[19] Tereshko V. Reaction-diffusion model of a honeybee colony's foraging behavior. Lecture Notes in Computer Science 2000; 191: 807-816.

[20] Tereshko V, Lee T. How information mapping patterns determine foraging behavior of a honey bee colony. Open Systems \& Information Dynamics 2012; 9(2): 181-193.

[21] Tereshko V, Loengarov A. Collective decision-making in honey bee foraging dynamics. Computing and Information Systems Journal 2005; 9(3): 1.

[22] Yang XS. Engineering optimizations via nature-inspired virtual bee algorithms. Artificial Intelligence and Knowledge Engineering Applications: A Bioinspired Approach. Springer Berlin Heidelberg 2005:317-323.

[23] Bahriye Akay, Dervis Karaboga. A modified Artificial Bee Colony algorithm for real-parameter optimization. Information Sciences 2012; 192: 120 - 142.

[24] Basturk B, Karaboga D. An artificial bee colony (ABC) algorithm for numeric function optimization, in: IEEE Swarm Intelligence Symposium, 2006, 8(1): 687-697.

[25] Rashedi E, Hossein N, Saeid S. GSA: A Gravitational Search Algorithm. Information Sciences 2009; 179(13): 2232-2248.

[26] Wolpert DH, Macready WG. No free lunch theorems for optimization, IEEE Transactions on Evolutionary Computation 1997; 1: $67-82$.

[27] Pham DT, Karaboga D. Optimum design of fuzzy logic controllers using genetic algorithms, Journal of Systems Engineering 1991; 1: 114 - 118.

[28] Holland J, Adaptation in Natural and Artificial Systems, MIT Press, Cambridge, MA, 1992. 
[29] Tang KS, Man KF, Kwong S, He Q. Genetic algorithms and their applications, IEEE Signal Process. Mag. 1996; 13(6): $22-37$.

[30] Dyer JD, Hartfield RJ, Dozier GV, Burkhalter JE. Aerospace design optimization using a steady state real coded genetic algorithm. Applied Mathematics \& Computation 2012; 218(9): 4710-4730.

[31] Tasi CW, Lin CL, Huang CH. Microbrushless DC motor control design based on real-coded structural genetic algorithm, IEEE/ASME Transactions on Mechatronics 2011; 16(1): 151-159.

[32] Valarmathi K, Devaraj D, Radhakrishnan TK. Real-coded genetic algorithm for system identification and controller tuning. Applied Mathematical Modelling 2009; 33(8): 3392-3401.

[33] Eberhart R, Shi Y, Kennedy J. Swarm Intelligence, Morgan Kaufmann, San Fransisco, CA, 2001.

[34] Andrews PS. An investigation into mutation operators for particle swarm optimization, in: Proc of the IEEE Congress on Evolutionary Computation, 2006: 1044-1051.

[35] Stacey A, Jancic M, Grundy I. Particle swarm optimization with mutation, in: Proc. of the IEEE Congress on Evolutionary Computation 2003; 2: 1425-1430.

[36] Karaboga Nurhan. Digital IIR filter design using differential evolution algorithm. Eurasip J. Appl. Signal Process 2005; 8: 1-9.

[37] Lampinen J. A constraint handling approach for the differential evolution algorithm. Evolutionary Computation, 2002; 2: 12-17.

[38] Ilonen J, Kamarainen JK, Lampinen J. Differential Evolution Training Algorithm for Feed-Forward Neural Networks. Neural Processing Letters, 2003; 17(17): 93-105;

[39] Paterlini S, Krink T. High Performance Clustering with Differential Evolution. The 2004 IEEE Congress on Evolutionary Computation 2004; 2: 2004-2011.

[40] Karaboga D, Akay B. A comparative study of artificial bee colony algorithm, Applied Mathematics \& computation 2009; 214 (1): 108-132.

[41] Karaboga D, Basturk B. On the performance of artificial bee colony (ABC) algorithm. Applied Soft Computing 2008; 8: 687-697.

[42] Zhan ZH, Zhang J, Li Y, Chung SH. Adaptive Particle Swarm Optimization. IEEE transactions on systems, man, and cybernetics part B: cybernetics 2009; 39(6): 1362 - 1381. 